\title{
Thuriah Medical Center -Riyadh Strategic Plan 2016-2019
}

\author{
Article by Geethamma Jolly \\ RN-MSN, Texila American University, Saudi Arabia \\ Email:- christy20042001@yahoo.com
}

\section{Message from TMC Chief Executive Officer}

Since it opened in 01-01-2001 Thuriah Medical center has grown and developed. In its more than 14 years of operation it has undergone important changes to meet the safety and quality requirement for the provision of quality patient care. In its entirety, the center is committed to provide reliable, safe and quality healthcare to its patients. It has endeavored to meet international standards, aim to satisfactorily meet and exceed patient expectation with increased patient satisfaction.

This Strategic Plan will serve as guide of the center in achieving its goals for the next three years. In behalf of the Executive Committee, the undersigned appreciates all those, who, in one way or another have contributed to the creation of this plan.

\section{Executive summary}

This Strategic Plan is a step by step guide used by the Executive Committee that outlines the means to reach the goals of Thuriah Medical center for the coming three years (20162019). Through a series of meetings, the committee was able to identify the measurable set of objectives, actions and strategies for the defined strategic goals. The plan is also the organization's process of defining a long term plan of action which shall help in making sound decisions on allocating its resources to pursue this strategy, including its capital and workforce.

All members of the Executive Committee participated in the planning stages and extended extra effort to carry out its plan. With the collaborative effort of all concerned, it shall ensure that the center vision and mission will be a reality. The plan also serves as a master plan in having an enhanced center service that is according to international standards.

Along with a continuous process to renew, modify and revolutionize center processes and procedures as initial steps in giving patients the best care they deserve, this plan shall result to patient satisfaction that is next to quality care and patient safety. Likewise, aside from making the business grow, this plan once completely met and implemented with the great support from all the staff will not only result to high quality service but more patient referrals that will benefit everyone in the long run.

The strategic plan will be reviewed annually by the Executive Committee to guarantee that $\mathrm{TMC}$ is on the right track in realizing all the enumerated steps, goals and strategic initiatives. The Governing Body of the Thuriah Medical Center has given its approval on this 3-year plan.

\section{Service profile $\&$ environmental monitor}

Thuriah Medical center Riyadh was inaugurated on 01-01-2001 and it is situated in the capital city of the Kingdom of Saudi Arabia which has a population of approximately 5.7 million people. The center is located in a fast rising business community area where a boom in construction has been noted. TMC is a specialized in Assisted Reproductive Technology devoted to provide safe and quality patient care. As part of it goals, the center leaders have developed a plan and care of services which is consistent with the organization's mission to deliver reliable quality healthcare. TMC Riyadh is fully computerized and equipped with the latest ART technology and is keen to provide modern and distinguished ART services with 
South American Journal of Management

Special Edition 2016

the exception of high rate of pregnancy. It aims to be the leading healthcare provider in gulf region.

Another of our strategic goals is research: to spearhead the agenda for research in reproduction and the development of both the current and future generations of clinical investigators in the reproductive sciences. Thuriah Medical Center staffs to have measureable impact on the reproductive care of our patients that can spread worldwide, and to takes maximum advantage of our research, and support activities.

\section{TMC riyadh \& its custom}

Thuriah Medical Center-Riyadh is providing services to many fertility patients from different sectors of the community composed of both local residents and emigrants. Among these clients are cash patients, It also deals with around deferent polyclinics and hospitals in Riyadh area for referrals to consultants and high-end Assisted Reproductive Technology (ART) services.

TMC-Riyadh undertakes the Scientific Lectures inviting health professionals from various hospitals in Riyadh for continuous medical education and at the same time introduce the services and facilities of the center and promote goodwill among healthcare professionals in the area. It is expected that through the new facilities that it offers, the center will reach new heights quality \& patient safety wise. TMC-Riyadh offers its services to the great population of Riyadh through the proper means and technique as part of the realization of this Strategic Plan.

\section{The population of riyadh}

Saudi Arabia is a desert country encompassing most of the Arabian Peninsula, with Red Sea and Persian Gulf coastlines. Known as the birthplace of Islam, its home to the religion's 2 most sacred mosques: Masjid al-Haram, in Mecca, destination of the annual Hajj pilgrimage, and Medina's Masjid an-Nabawi, burial site of the prophet Muhammad. Riyadh, the capital, is a skyscraper-filled metropolis

Riyadh, the capital city of the Kingdom of Saudi Arabia has grown and as an indication of the growth of urbanization from available population figures. The city has experienced very high rates of population growth, from 2,000,000 inhabitants in the 1990's to over 5.7 million in 2014. With this figure, the TMC Riyadh is situated in an area where it can touch base with its target market. With modernization comes the requirement for quality and more updated services like high end and latest medical service that the Assisted Reproductive Technology patient's needs.

Population of Saudi Arabia as of 1 January 2015, the population of Saudi Arabia was is $30,770,375$ people ( 30.8 million). This is an increase of $2.55 \%$ people compared to population of 29164106 the year before. In 2014 the natural increase was positive, as the number of births exceeded the number of deaths by 466917 . Due to external migration, the population declined by 18665 . The sex ratio of the total population was 1.233 (1 233 males per 1000 females) which is higher than global sex ratio. The global sex ratio in the world was approximately 1016 males to 1000 females as of 2014. Below figures show the Population break-up of Riyadh: 


\begin{tabular}{|c|c|c|}
\hline By Nationality & Percentage & Total \\
\hline Saudi & $68 \%$ & 4.0 Million \\
\hline Others & $32 \%$ & 1.7 Million \\
\hline
\end{tabular}

\begin{tabular}{|c|c|c|}
\hline By Gender & Percentage & Total \\
\hline Male & $\mathbf{5 5 \%}$ & $\mathbf{2 . 9 8}$ Million \\
\hline Female & $\mathbf{4 5 \%}$ & $\mathbf{2 . 7 2}$ Million \\
\hline
\end{tabular}

\begin{tabular}{|c|c|}
\hline By Age & Percentage \\
\hline $0-20$ years & $35 \%$ \\
\hline $21-50$ years & $60 \%$ \\
\hline $51-60$ years & $5 \%$ \\
\hline
\end{tabular}

Riyadh is divided into 15 municipalities, in addition to the Diplomatic Quarter. Olaya District is the commercial heart of the city, with accommodation, entertainment, dining and shopping options. As a capital of Saudi Arabia, Riyadh has received millions of visitors of different backgrounds from all over the world. The population as shown in the table above is made up of foreigners from Africa, South Asia, Europe and the Middle East, many of whom remained and became residents of the city.

The Industrial areas are located on the East and the North-East of the city, including some of world's largest factories of oil-related industry, high-tech, low-tech and agriculture. Once a small walled city, Riyadh has developed into a dynamic metropolis over the years. Along with the urban areas of Dhahran, Dammam and Khobar, Riyadh has become a focal point for both travel and trade. In addition to being the center of power, the city is also a commercial hub. Numerous educational, financial, agricultural, cultural, technical, and social organizations have set up base here.

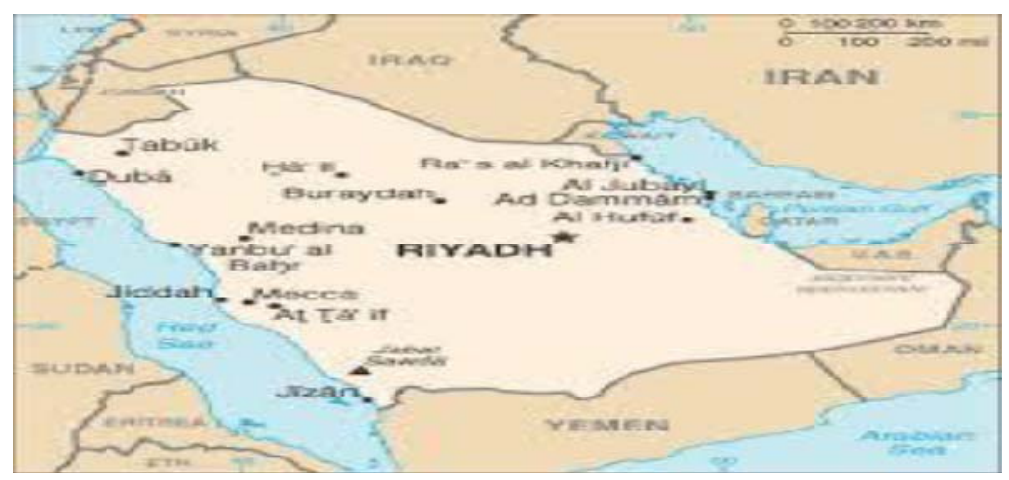

\section{Market structure conduct performance analysis}

There are many clinics, polyclinics, small hospitals in Riyadh that provide minor and preventive health care, while hospitals provide general medical care and offer services and facility for more complicated cases and procedures. The Saudi government is now focused on the continuous improvement of Saudi health facilities and expertise with the increase in the number of hospitals, medical and paramedical schools to encourage Saudis to participate in healthcare services. The competitors of TMC Riyadh are classified as follows:

* Government hospitals

* Private Hospitals

\section{Government hospitals}

- Advantage of government hospitals:

o The treatment cost is very less than private hospitals. 
South American Journal of Management

Special Edition 2016

o Highly equipped with the latest technology

0 Very high quality consultants

- Disadvantage of the government hospitals:

o Long Waiting Time

- Government hospitals in Riyadh

o King Fahad Medical City.

o King Faisal Specialized hospital.

o Riyadh Military Hospital.

o National Guard Hospital.

o King Khaled University Hospital

o King Saud University Hospital

\section{Private Hospitals}

- Advantage of private hospitals

o The main advantage of the private hospitals in Riyadh is that they have experienced and highly qualified Saudi doctors.

- Disadvantage of the private hospitals

o Crowdedness

o Parking

o Some services not available

- Private hospitals in Riyadh for ART services

o Dallah Hospital

o Soliman Al Habib Medical Group

o Kingdom Hospital

o Saudi German Hospital

\section{Cost of entry to the market}

The cost of entry to the market from new player is extremely high, more over the knowhow and the brand building which usually takes more time in the health care sector might affect the business profitability for new comers, thus, preventing them from getting a competitive advantage. However, if expansion and additional new centers are done by existing health sector players like Al Habib, Dallah this will increase their market share and will help them to gain a competitive advantage as the market is not completely saturated and their cost of expansion and building new hospitals will be less from the new entrants which will increase their profitability too. The cost of continued existence from the market is extremely huge, and if any player did not plan for his existence for long time he will lose a lot.

\section{Conduct of industry}

Due to fast growing medical services and insurance business in Riyadh area and very high competition, many new health care providers have entered the market. Our main competitors adapt a variety of strategy to gain comparative advantage through better medical staff that is educated from western organizations and diversified allied health staff. In addition, most of competitors are now under process of JCI accreditation. More hospitals are concentrating on "Patient Satisfaction" via better luxurious rooms, less waiting time to get the services, qualified and very well trained front line staff to deal with demanding patients. Moreover, they are expanding locally within Riyadh and they are adding new sub-specialties that they do not have before which will lead to the possibility of increasing the percentage of their market share leading to a better competitive and advantage position.

As for TMC Riyadh, most of its doctors are hired from one source, hence, losing its competitive advantage in this area. It used to be known as ART Center, however it retained its strength by having a strong IVF Department and some services that other hospitals do not have like some state of the Genetic Laboratory services. It is now expanding to cover other sub-specialties which include all ART procedures and adding minimal invasive surgery for 
ART services. All these improvements are expected to aid in gaining the TMC's position and competitive advantage.

\section{Performance of competitors and health care providers}

As per data gathered, some of hospitals and medical centers show the following advantages or strengths:

1. Front line desk multinational, the ratio is 1:1 Saudi/Non-Saudi.

2. Male and Female furniture waiting areas were seen which includes central table with a stand of magazines (medical, cultural) and newspapers.

3. There is Information Center in the main entrance occupied, presentable employees, attending telephone calls and meeting customer to answer any inquiry.

4. Flow of patients is easy because there is one reception for each specialty of reservation, registration, and issuing receipts for services and investigation.

5. Day case surgery there are different classes with different decorations and very good furniture with special rooms were noticed to satisfy and comply with standard and social class of the patient.

6. Flow of customers in the pharmacy is excellent; there is electronic numbering system and four counters to receive patients and delivering medications.

7. Posters are fixed in movable panels and brochures distributed in each counter and waiting area having a high quality of glossy papers with high resolution of pictures.

8. Very wide waiting area with good furniture.

While the weaknesses of these private hospitals include:

1. Long waiting time for reservation of appointments.

2. They are refusing the complicated ART cases.

3. They don't have Genetic Laboratory Services.

4. They don't have Saudi Fertility Group -Symposium

5. No ART article publication

\section{Thuriah medical center riyadh performance analysis}

\section{Micro analysis}

- The micro environment plays a critical role in the success and behavior of a business.

- This involves organization that deals with the center on a regular basis. For example, suppliers, competitors, customers and employees. They are all members of the microenvironment.

- These groups are stakeholders of the business. They all have a direct interest in the activities of the center and are clearly affected by its actions.

- Managers regularly interact with others in the micro-environment and their decisions have a direct effect on them e.g. a decision to expand may mean an increase in supplies, more deliveries and greater profits. At the same time these stakeholder groups can have a direct impact on the firm.

- Labor shortages in the local labor market may make it more expensive to recruit as competition from $\mathrm{MOH}$ and other private hospitals.

- Competitors launching new hospitals like (Suliman Al Habib, Dallah) will take more market share and changes in customer tastes may require a rethinking of the marketing strategy.

- Delays by suppliers may lead to cash-flow problems and problems with patients which affect the business.

- Satisfactions of employees affect the business.

\section{Competitors details analysis}

TMC Riyadh has many unique services and advantages as compared to its competitors from both the private and government sectors: 


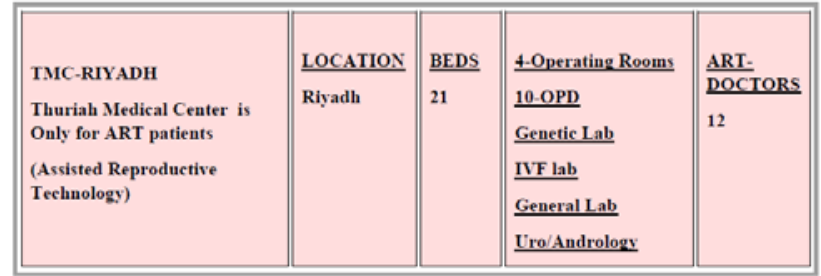

\section{Private hospitals/ direct competitors}

\begin{tabular}{|l|l|l|l|l||}
\hline Hospital & Location & Beds & ICU Beds & Doctors \\
\hline \hline Al Hammadi Hospital & Olaya, Riyadh & 400 & 16 & 250 \\
\hline \hline Dallah Hospital & King Fahad Road & 315 & 18 & 250 \\
\hline \hline Suleiman Al Hahih & Olaya, Riyadh & 250 & 20 & 150 \\
\hline \hline Kingdom Hospital & Exit 12 & & 15 \\
\hline \hline Saudi German Hospital & & 300 & 15 \\
\hline
\end{tabular}

There are also Ministry of Health hospitals that provide free treatment to patients and some provides referrals as part of the hospital's agreement with $\mathrm{MOH}$.

\section{Macro analysis}

- This involves factors outside of the direct control of the business.

- These macro-factors such as the economy, government policy and social change can have a significant effect on business.

- A change in the foreign exchange rate can affect the cost of supplies.

- The ageing population has increased demand for healthcare resources.

- The macro-environment can be analyzed using PESTEL analysis.

\section{PESTEL analysis}

As part of the external analysis, a deep analysis of the current situation of Riyadh that directly and indirectly affecting the center are given below:

\section{Political}

Firstly the political environment concerns the role of the government and its effects in an organization. It also includes the extent to which the government intervenes in the economy. The political condition in KSA can be considered as an open market and stable but these days there are some political problem in the Middle East region which may affect the overall business. However, the government is encouraging private sectors growth. In this manner, the government of KSA is willing to accept new investors but under some restrictions in order to increase the number of Saudi nationals workforce in every organization for example.

\section{Economical}

KSA has one of the largest economies in the world in line with market exchange rates, it is also considered to be the largest in terms of purchasing power hence it can be said that there 
is a bigger opportunity for a new company to become successful in operating within KSA. The continuously growing market economy of KSA has been a good indicator that the new company will be known in the marketplace. There is also a very obvious increase in insurance business as well as obligatory insurance for expatriates all over the Kingdom.

\section{Social condition}

KSA is known to have consumers who are willing to accept new entrants as long as it meets their needs for a certain product or service but it must meet the nature of society of an Islamic country. The social condition of KSA is also considered to be multicultural affecting the behavior of each target market.

\section{Technological}

KSA has been able to utilize its advance technology. This includes their acceptance of information technology especially for business operations. This aspect will give a new company a big chance to grow in the market.

\section{Environmental factors}

Environmental factors include the weather and climate change. Changes in temperature can have an impact on the business especially during hot summer season which is considered as summer vacation months (June, July, and August).

\section{Legal factors}

Many significant legal changes which affect the organization's actions such as Saudization, licensing requirements such as medical license and obligatory insurance are just some of the clear example.

\section{We are in temporary competitive parity situation}

Thuriah Medical Center is on competitive equivalence situation with average accounting performance. This position is temporary and if measures are not taken to improve its services and core competency as strong health care provider with reputable Assisted Reproductive services and improved customer service level to patients, it will be losing more market share.

\section{Business strategy}

Currently cash patients is our main clients, our business strategy is within economy of scale competing by lowering our prices in relation to the same category of competitor and this increases our growth revenue but decreases our profitability sharply. Nevertheless, when the operation becomes under pressure, the organization adapts a cost control strategy that affects the vital functions of operations.

\section{Environmental threat}

The five forces model of environmental threat designed by Professor Michel E. Porter was used for Micro analysis. It identifies the five most common threats facing any firm by their local competition environments and the condition under which these threats are more or less likely to be present. Any organization seeking a comparative advantage must reduce these five forces power.

\section{The five forces model of environmental threat analysis}

Professor Michael Porter's famous Five Forces of Competitive Position model provide a simple perspective for assessing and analyzing the competitive strength and position of a corporation or business organization. It provides a framework that shows that an industry is influenced by five forces, as follows:
1- The threat of new entry
2- Threat of competition 
South American Journal of Management

Special Edition 2016

3- Threat of substitute

4- Threat of buyers' (patients)

5- Threat of suppliers

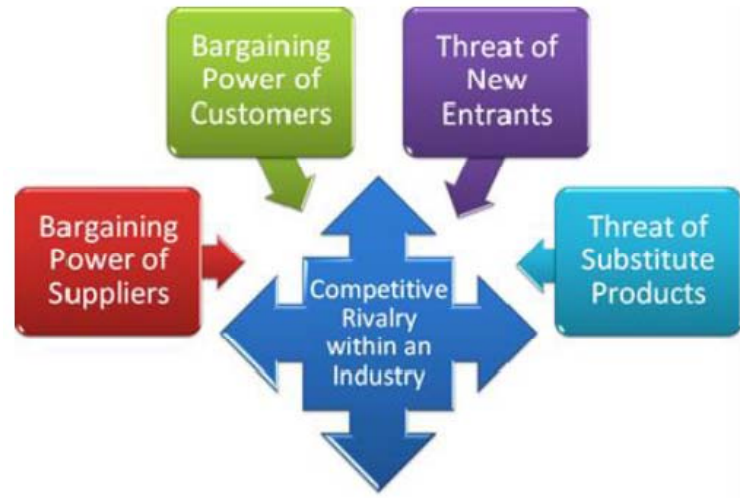

\section{A graphical representation of Porter's Five Forces}

This analysis states that by understanding the competitive forces and their underlying causes, reveals the roots of an industry's current profitability while providing a framework for anticipating and influencing competition (and profitability) overtime. Further, a healthy industry structure should be as much as competitive concern to strategists as their company's own position. Most importantly, understanding industry structure is also essential to effective strategic positioning as defending against the competitive forces and shaping them in a company's favor are crucial to strategy. Using the above as reference, when an analysis of the market is done, it will result to the following:

\section{Threat of entry}

The cost of entry for new organizations outside the health care sector is extremely high specially when they do not have the knowhow, cost of entry is higher than the profit that could be gained from building new hospitals but this changes when it comes to an already existing player in the market who already have market share and building new hospital will get him a competitive advantage. Governmental regulation: government regulation favors the investment in new hospitals with their special programs for funding such hospitals, however it affects the possibility of getting professional staff who have the needed know how or talent required.

\section{Barriers to entry for other hospitals include}

The powerful brands of many hospitals as compared to Thuriah Medical center, Soliman Al Habib Medical Group and Dallah, which any new player will not have and this alone is a strong barrier for entry for new ART centers and could lead to a competitive disadvantage for new hospitals.

\section{Threat of rivalry}

Most of the organizations in the market are roughly from the same size and the hospitals of the same size are few as market is in a partial competitive parity, many players of the same category in the market that could affect the existence of others all will have and is having a market share. The market is homogeneous with some differentiation of 2 hospitals like Dallah and $\mathrm{Al} \mathrm{Habib}$, however are seeking a niche in the market and considered the main player in the market. Apart from that, all others are having the same performance. 


\section{Threat of substitute}

The substitute for the hospitals of our size are polyclinics and small medical centers but their power is very low as they do not have professional staff, advanced ART equipment's or the capacity for genetic laboratory services.

\section{Threat of suppliers}

The threat of suppliers is very strong. The supplier industry either pharmaceutical companies or medical device companies are dominated by small number of firms controlling the prices in the market and they all sell their own unique and specialized differentiated services which are the heart of the operation in any hospital. The supplier market are ready working on the market have little threat from substitute from other products like the generic drugs for the pharmaceutical companies or the low quality Chinese made equipment for the medical device industries as they are not as efficient as the main players on the market but they are less cheaper than them. Moreover TMC due to its old problems with suppliers is considered as medium important customers for these suppliers due to payment problem. In conclusion, the suppliers have an extra ordinary power that could control the health care market and that could threat the performance of our organization if not taken into consideration.

\section{Threat of patients}

The segments of population in Riyadh requiring health care are huge. The patient power is mostly transferred to the $\mathrm{MOH}$ where it gives them a variety of hospital to choose from. Patients usually get the hospital with best ART services and high satisfaction level from the network they wants. $\mathrm{MOH}$ and patients exerts a huge power in the health care market and our center is not fully saturated yet meaning that our clients has a huge power as we need more client to get our targeted performance. While for other hospitals the power of client is not that huge because they are already saturated with patient who gives them the power to move their prices up with the $\mathrm{MOH}$ and other clients

\section{Development of TMC Riyadh Strategic Plans}

The Executive Committee in developing the Strategic Plan for the coming three years (2016-2019) with the hope that effective strategies and perceived innovations will result to greater benefit and that the center will be better positioned for success in achieving its mission and vision.

A series of meetings were conducted to review the previous plan prepared in 2013, update and develop it to match the current needs of Thuriah Medical Center in line with the Executive Committee come up with better solutions that shall enable the center to perform better in consideration of its aim to provide safe and quality health care to its patients. Henceforth, the value of having a Strategic Plan that shall align all the efforts and activities of the center in order to reach a new level of performance was established. The core activities to develop a hospital plan are based on the following steps: 
South American Journal of Management

Special Edition 2016

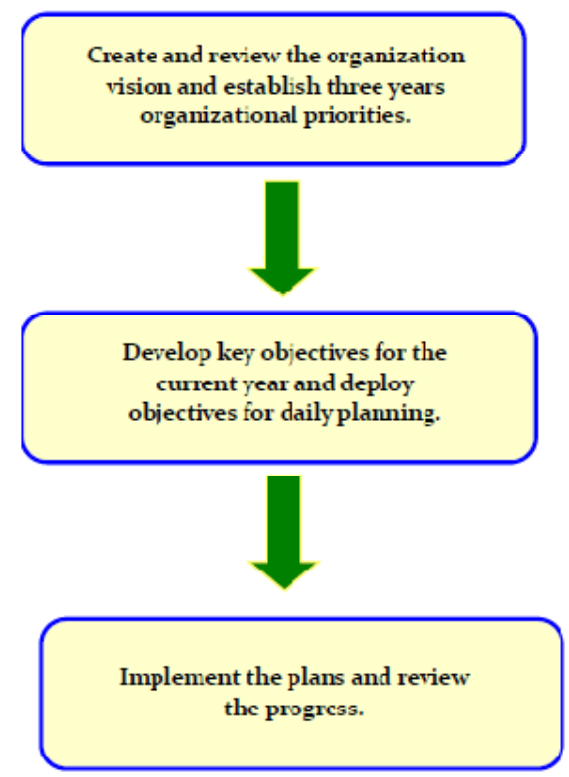

\section{Steps in Strategic planning}

\section{Step 1: External analysis}

\section{Purposes}

- Sets the tone for organizational culture and commitment to excellence;

- Defines the "community" for service goals and sets territorial boundaries for future operations;

- Defines and assesses the actual and potential markets and customers;

- Identifies opportunities and constraints;

- Provides a basis for "benchmarking": Comparing the organization to neighbors and competitors.

\section{Data collected}

- Regulatory Environment;

- Competition;

- Customer needs, expectations, preferences, and priorities;

- Demographic forecasting:

o Determines characteristics of customer groups to be served, e.g., gender, language, ethnicity;

o Provides information as to types and quantity of products and services needed and demanded.

\section{Step 2: Internal analysis}

Purpose: To develop a balanced picture of the organizations limitations, strengths and opportunities for further development.

\section{Data assessed}

- Types and utilization of services;

- Patient Mix

- Practitioner characteristics, treatment patterns and performance;

- Financial performance;

- Facilities inventory;

- Organizational assessment (evaluation of the current effectiveness of infrastructure and culture). 


\section{Step 3: Issue analysis}

The issue analysis took the form of a SWOT analysis, using the external and internal data collected analyzed in steps 1 and 2:

\begin{tabular}{|l|l|l|l|}
\hline S & Strengths & W & Weaknesses \\
\hline O & Opportunities & T & Threats \\
\hline
\end{tabular}

The detailed SWOT Analysis

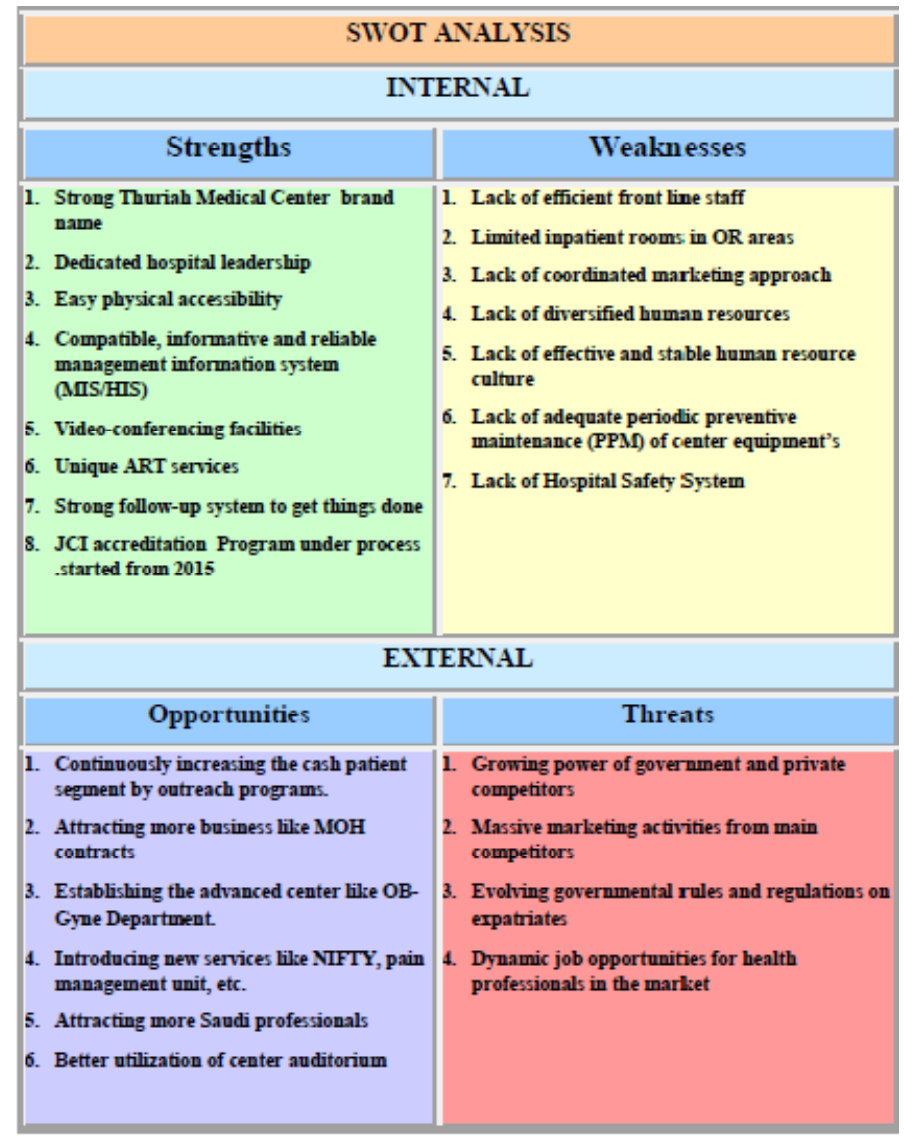

\section{Step 4: Business intelligence}

The key to thriving in a competitive marketplace is staying ahead of the competition. Making sound business decisions based on accurate and current information takes more than intuition. Data analysis, reporting, and query tools can help business users wade through a sea of data to synthesize valuable information from it - today these tools collectively fall into a category called "Business Intelligence. "This process involved data gathering, storing, analyzing, and providing access to data to help enterprise users make better business decisions. Business Intelligence applications include the activities of decision support systems, query and reporting, online analytical processing, statistical analysis, forecasting, and data mining to determine the future or desired outcome that should be taken as beginning point for this Strategic Plan prior to implementation. 
South American Journal of Management

Special Edition 2016

\section{Step 5: Development/Review/Revision of Mission, Vision, and Core Values:}

The Vision, Mission and Core Values of TMC Riyadh was reviewed, revised and approved as below.

Vision

Strive to maintain leadership in the provision of world class reproductive health services.

\section{Mission}

At Thuriah Medical Center, we are dedicated to the provision of highly specialized reproductive health services by a highly qualified experienced team enhanced by commitment and compassion to our patient's needs.

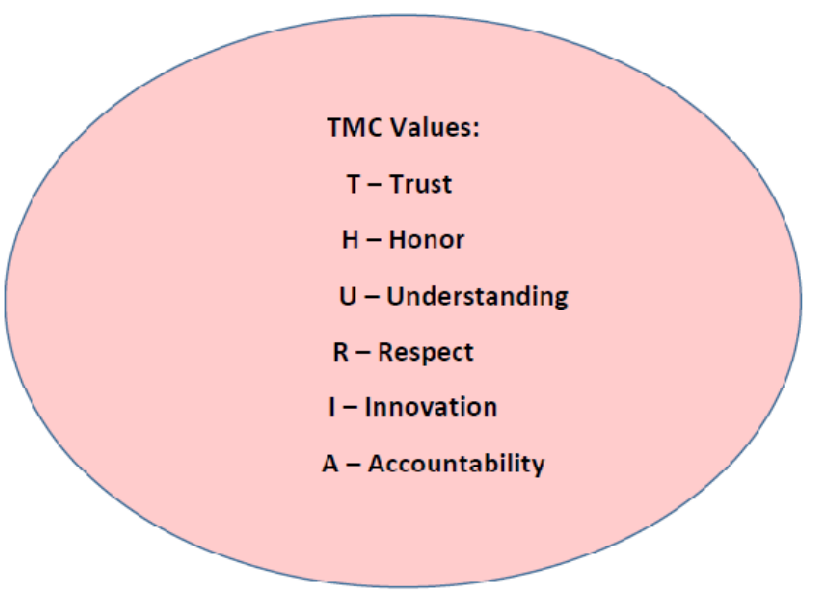




\section{TMC Mission, Vision \& Core Values}
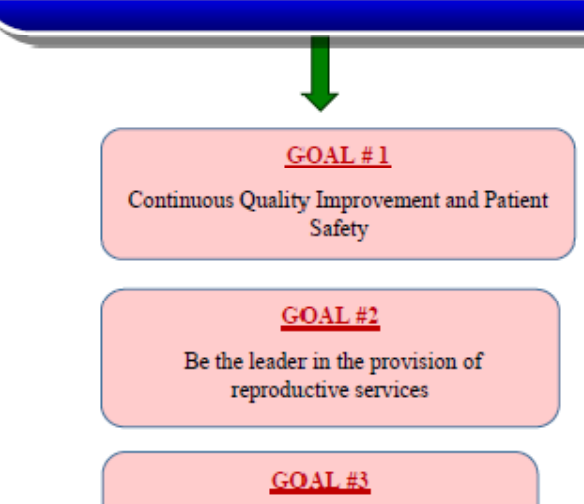

Customers as partners in decision making

$\underline{\text { GOAL \#4 }}$

Trained and committed Human Resource

\section{GOAL \#5}

Financial Growth

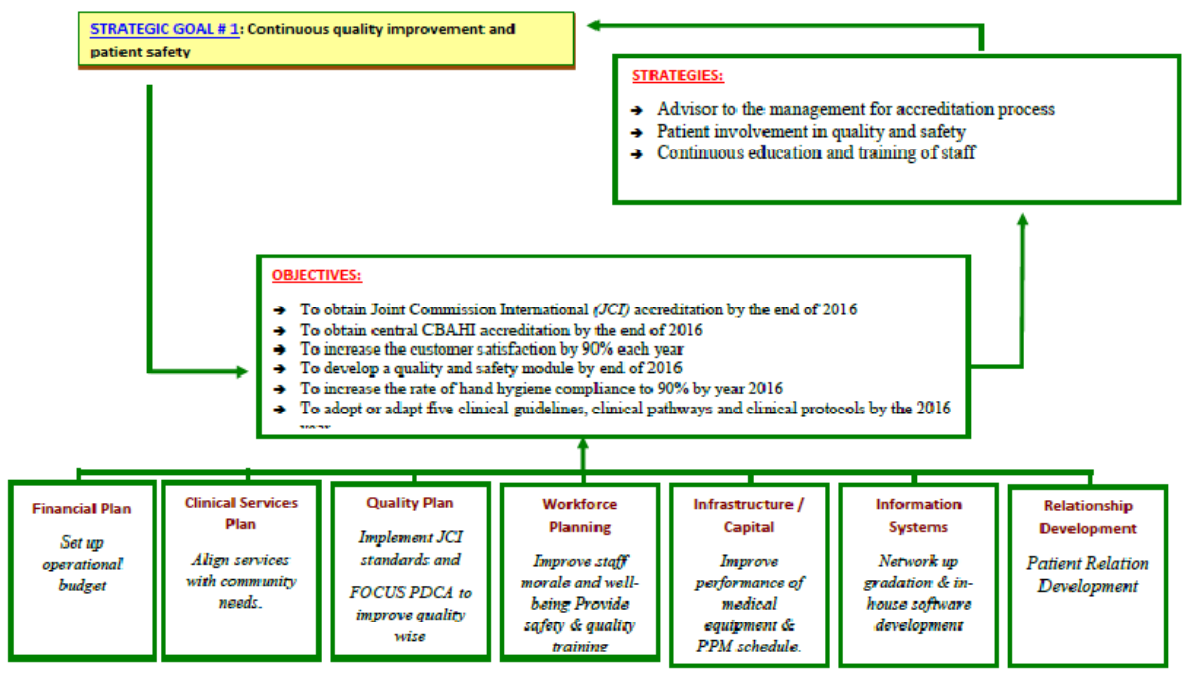


South American Journal of Management

Special Edition 2016

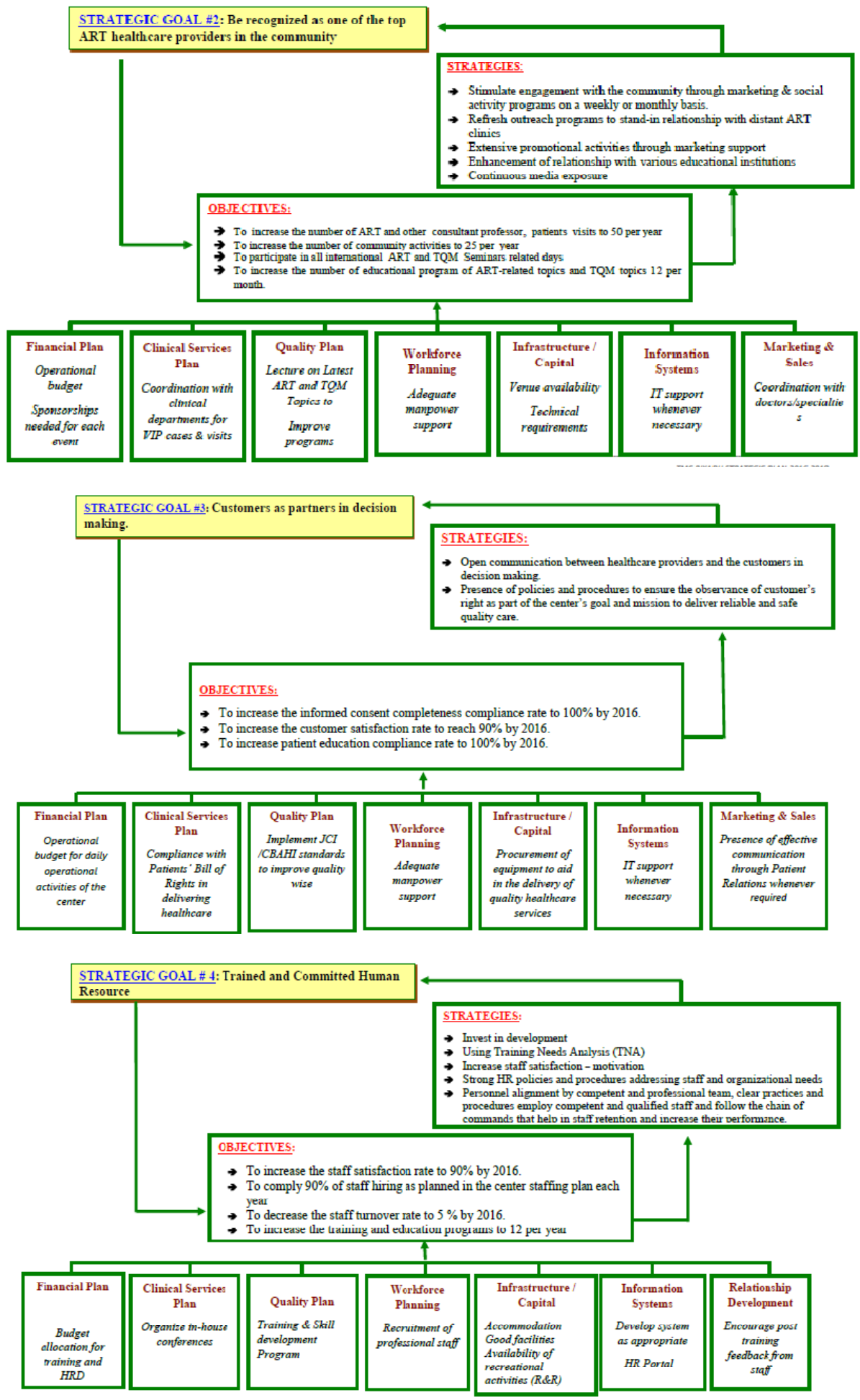




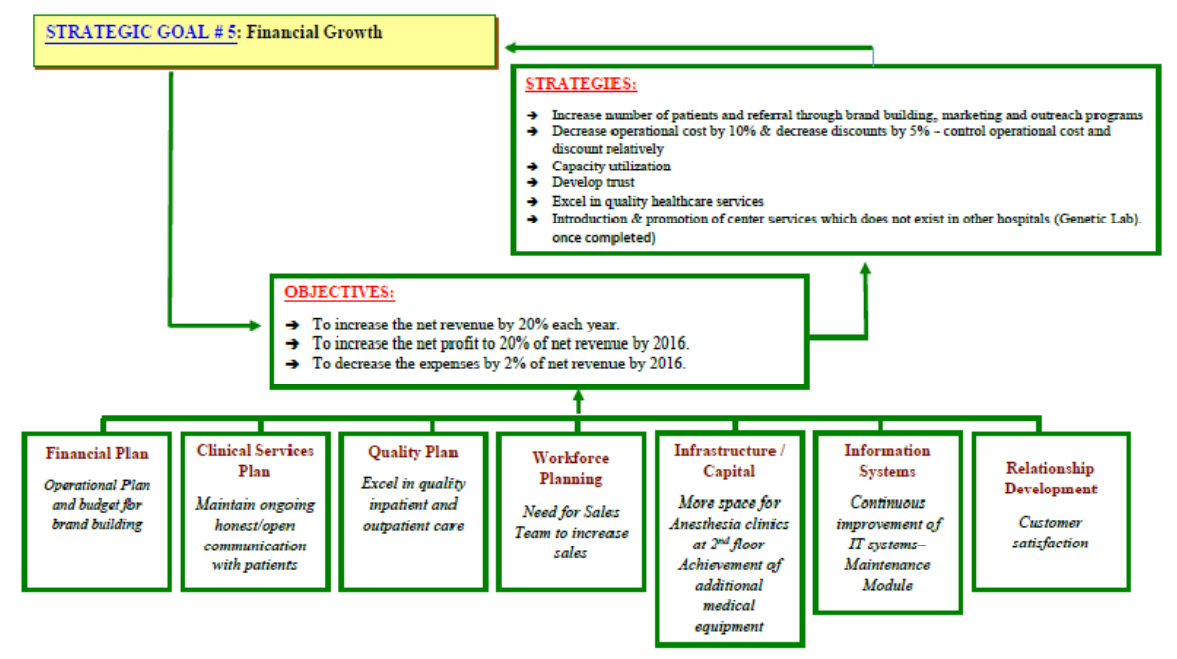

TMC has adopted the FOCUS-PDCA Methodology for Quality Improvement Projects.

\begin{tabular}{|c|c|}
\hline $\mathbf{F}$ & $\begin{array}{l}\text { Find an Opportunity for Improvement } \\
\text { - Improvement efforts should be focused on improving patient care reducing costs and } \\
\text { fulfilling center's mission and goals. } \\
\text { - Review applicable standards and guidelines. } \\
\text { - Analyze collected data to evaluate customers' needs. } \\
\text { - Outline the basic problem and the desired outcome. }\end{array}$ \\
\hline O & $\begin{array}{l}\text { Organize a Team } \\
\text { - Improvement may span several departments. } \\
\text { - Identify and involve stakeholders i.e., physicians, nurses, administration, finance, } \\
\text { human resources, etc. } \\
\text { - Select multidisciplinary team members, who do or know the process / problem. } \\
\text { "Ownership" of the solution helps ensure future compliance. }\end{array}$ \\
\hline C & $\begin{array}{l}\text { Clarify the Current Process } \\
\text { - Improvement cannot take place until the current process is fully understood by all } \\
\text { team members. } \\
\text { - Draw a flow chart of the problem. } \\
\text { - Obtain input from all affected areas. } \\
\text { - Collect or obtain data relevant to the process and desired outcomes. }\end{array}$ \\
\hline $\mathrm{U}$ & $\begin{array}{l}\text { Understand the Problem and Process Variation } \\
\text { - Improving the process means identifying all possible causes and variations developing } \\
\text { solutions to achieve the desired outcome. } \\
\text { - Obtain additional information that is required: collect data benchmarking best } \\
\text { practice, etc. }\end{array}$ \\
\hline $\mathbf{S}$ & $\begin{array}{l}\text { Select the Improvement } \\
\text { - Analyze alternative solutions and process improvement. } \\
\text { - Choose the best solution that will achieve the desired outcome. } \\
\text { - Develop approval with a summary of required information, expected outcomes, } \\
\text { resources, time frames, team membership, etc. }\end{array}$ \\
\hline
\end{tabular}




\begin{tabular}{|c|c|}
\hline $\mathbf{P}$ & $\begin{array}{l}\text { Plan the Improvement } \\
\text { - An improvement project will be planned with goals and target according to the } \\
\text { established ongoing objectives and new objectives. } \\
\text { - The plans will be communicated to all concerned departments. } \\
\text { - Action team members will be selected to work and monitor the success of the plan } \\
\text { with a team leader among them. } \\
\text { - Tasks will be assigned to the action team members, a checklist and realistic time } \\
\text { frames will be developed for its realization. } \\
\text { - Team members will be responsible for obtaining necessary data, monitoring the } \\
\text { project, and keeping track of it. The overall outcome is the responsibility of concerned } \\
\text { department and the QPS Department } \\
\text { - All departments that will be affected by the projects will be notified of the } \\
\text { implementation by the action team members }\end{array}$ \\
\hline D & $\begin{array}{l}\text { Do the Improvement } \\
\text { - After the project planning, the implementation strategies will be identified to be } \\
\text { implemented systematically. } \\
\text { - All the people involved in the process from the Action Teams to the subordinates who } \\
\text { will be directly involved in its execution will be trained. } \\
\text { - In the process data will be collected including negative and positive outcomes and the } \\
\text { required checklist will be updated as per outcome. } \\
\text { - The improved process will be kept and maintain and defects will be rectified. It will } \\
\text { be kept on track by monitoring. }\end{array}$ \\
\hline C & $\begin{array}{l}\text { Check the Results } \\
\text { - The result of the implemented strategies will be analyzed to measure the outcome. } \\
\text { This question is necessary to be raised at this time to see the results: "Did the change } \\
\text { lead to the expected improvement?" } \\
\text { - Compare the data collected with that collected during and after implementation to } \\
\text { ascertain, if the project goals were met. } \\
\text { - Check for any adverse consequences whether the change is acceptable to all involved. } \\
\text { - Continue to collect data to determine the effectiveness and compliance with the } \\
\text { strategic solutions. }\end{array}$ \\
\hline $\mathbf{A}$ & $\begin{array}{l}\text { Act to Hold the Gain } \\
\text { - If the project goals, change, and the desired outcome were met, it the improved } \\
\text { process shall be standardized throughout TMC where applicable. } \\
\text { - Necessary adjustments will be made to the policies and procedures to update and } \\
\text { adopt the improved processes. } \\
\text { - These changes will be communicated to employees who will be involved in its } \\
\text { performance by orienting or including it in the continuing education or career } \\
\text { development. } \\
\text { - Changes will be monitored and documented to identify any additional opportunities } \\
\text { for improvement. } \\
\text { - The success of any improvement project shall be owned by the action team members } \\
\text { and the departments involved in the process. }\end{array}$ \\
\hline \multicolumn{2}{|c|}{$\begin{array}{l}\text { Prioritization mechanism is focused on: High Risk; Problem Prone; High and Low } \\
\text { Volume; High Risk; Internal and External Customer Expectations; High Cost and } \\
\text { International Patient Safety Goals. } \\
\text { Outcome measures should reflect improvement in the following dimensions of quality: } \\
\text { Efficiency and effectiveness; Appropriateness; Availability; Timeliness; Maintenance and } \\
\text { continuity; Safety; Adherence to the Professional Ethics; and Ensuring Respect and Care (as } \\
\text { rights). } \\
\text { Vital Customer-Focused Functions: } \\
\text { - Patient Relation Committee }\end{array}$} \\
\hline
\end{tabular}


- Patient \& Family Education

- Customer Satisfaction Surveys

- Complaints and Compliment Management

The following tools will be utilized to assess and improve the implementation of this plan:

- Brainstorming

- Diagrams such as Affinity, Matrix, Force Field, Cause and Effect, Scatter Diagram

- Charts such as Pareto, Control and Run charts

- Flowcharts such as: Sequence and Process Flowcharts

- Criteria Ratings; Check Sheets; Histograms.

Improving support services like housekeeping, catering, security, front desk, etc

Innovation of products and treatments in addition to exploring new market areas

- International Visiting Professor Program

- Hire more diversified ART physicians

- Expansion of Genetic Lab services

- Expansion of pre anesthesia clinics

- Increase number of Technicians in IVF department

- Increase awareness about Thuriah Medical Center in surrounding countries

- Manage media exposure

\section{Continuous improvement of IT technology}

Enhancing patient care by providing a unified program for patient care through IT application like CRM (Customer Relationship Management)

Financial System: TMC Financial System was replaced in September 2015 with FOCUS E-Business suite for better performance, integrity and to be based on international standards like ERP (Enterprise Resource Planning) whose full implementation within the Group level is expected to be completed by January 2016.

Data Warehouse: At the moment the IT strategic committee is working on the program to centralize the reporting system so that higher administration could have one source of information for all the center with respect to revenue and patient census.

\section{System Up-gradation:}

Database Server: Ongoing the up-gradation of database server, which is divided into two sections as following:

Hardware: Upgrade to HP DL 320E G8, Along with more storage capacity, performance and scalability

Software: Upgraded the database server from SQL Server 2000 to SQL Server 2012, which is based on latest technology, along with the features of Automatic failover in case of disaster; enhance security, scalability and performance.

Exchange Server: Completed the up-gradation of exchange server (email server) from Server 2003 to server 2012 (HP DL 320) which is high performance server with latest configuration.

Client Server: Keeping in view to improve the services to the patients we have upgraded the client machines as well to give better services and to have faster performance when it comes to systems, in this regard following are the details:

Hardware: Dell Optiplex 360/380/520/755/760/780/9010 \&HP, ACER...CRT Monitors to LCD Display Screen

Software: Windows $7 \&$ Windows 8

In-House Software Development: IT Department is continuously trying to improve the efficiency and work flow among different departments, for that there are some modules which are being developed and also as part of MCI requirement.

- General Maintenance Module

- Upgrading the Bio-Medical Module

- Management Information System 
South American Journal of Management

Special Edition 2016

- HR Portal

Wireless internet service for patients

\section{References}

[1.] Central Board of Accreditation for Healthcare Institutions (CBAHI) National Hospital Standards, Edition (2015) Hospital Accreditation Guide

[2.] Goodstein LD, Nolan TM \& Pfeiffer JW (1992) Applied Strategic Planning An Introduction, Applied strategic Planning A Comprehensive Guide

[3.] http://www.revespcardiol.org/en/strategic-planning-in-healthcare-organizations/articulo/90147901/

[4.] JCI Standards Edition 2015; GLD 1.2

[5.] Minutes of Executive Committee Meetings

[6.] Riyadh Chamber of Commerce Research in Healthcare Statistics 2014

[7.] Resources for Hospital Strategic Planning

[8.] Saudi Arabian Information Resource

[9.] Strategic Management and Competitive Advantage - Concepts and Cases Second Edition, The Tools of Strategic Analysis by Jay B. Barney and William S. Hesterly

[10.] TMC Riyadh Mission, Vision, and Core Values

[11.] The Healthcare Quality Handbook by Janet A. Brown, R.N., C.P.H.Q.

[12.] The five competitive forces that Shape Strategy by Michael E. Porter

[13.] Wikipedia, the free encyclopedia

\section{TMC Riyadh Strategic Plan Approvals}

\section{Appendix A}

\section{Executive Committee Members}

General Manager- Dr. Hamad Sufyan Al Sufyan

Chief Executive Officer- Dr. Hussein Laqwer

Chief Medical officer - Dr. Abdullah Salih

Chief Nursing Officer- Ms. Geethamma Jolly

Chief Quality Officer- Dr. Amir Chohan

Chief Operating Officer- Ms. Rawia Sufyan

\section{Appendix B}

\section{Definitions \& Quality Concepts}

Strategic Planning is an organization-wide/system-wide, ongoing look into the future. It is a process based on an objective internal and external assessment that focus on current reality and the foreseeable future, and is driven by needs, priorities, feasibility, capabilities, and available resources. It is viewed as leadership's deliberate attempt to stop "spinning the top", at least on an annual basis, and ask some core questions such as:

- What are we doing?

- What should we be doing?

- What should we be doing next?

- How should we be doing it?

- What should we not be doing?

Time Frames in strategic planning refer to the expected completion of an objective. Strategic planning can be short term or long term goals. A year-long (short term) operational plan may be generated annually to support strategic plan implementation.

- Short term focus on 2-3 years (near future) with an annual review and update of an accompanying year-long Operational Plan.

- Long term is projecting the present into the future for 5-10 years. 
External Analysis is scanning and analyzing assessments from external environment such as the community, cultural/linguistic competency by collecting data to be analyzed and transformed into information for decision-making.

Internal Analysis is scanning and analyzing internal organization's limitations, strength, and opportunities for further development.

Issue Analysis is identification and prioritization of important organizational functions, key challenges, and opportunities. It takes the form of "SWOT" analysis using data collected and analyzed under external and internal analysis. SWOT stands for:

$$
\begin{aligned}
& \mathbf{S}=\text { Strength } \\
& \mathbf{W}=\text { Weaknesses } \\
& \mathbf{O}=\text { Opportunities } \\
& \mathbf{T}=\text { Threats }
\end{aligned}
$$

Mission Statement declares (what/who the organization is?) The overall, broad purpose and role of the organization related to desired services, permitted services, availability of resources, and commitment to meeting community needs. It is where the governance and management links are made to quality. The mission statement addresses:

- Commitment to quality in all organization activities;

- High priority commitment to patient care and safety;

- Commitment to competency and professional growth of employees and staff; and

- Commitment to serving the community.

Vision statement declares (what the organization strives to be), intents and aspirations for the future. According to Pointer and organizations must ask key questions when formulating the vision:

- What benefits and values should the organization be providing?

- How should the organization fulfill the interests and meet the needs and expectations of its stakeholders?

Core Values, value statements or guiding principles is a listing or organizational values that support the mission and vision statements and guide strategic planning, decision-making, and provision of all services. Core values are related to the following dimensions of care and quality:

- Respect for persons

- Quality of care

- Acceptability of care

- Professional competence

- Effectiveness of care

- Employee empowerment and satisfaction

- Continuity of care and services

- Appropriateness of resource utilization

- Management of information and technology

- Safety

- Accessibility

Critical Success Factors are those things the organization must do to achieve the goals and vision. Once these are identified, they are incorporated into the strategic plan as strategies and objectives, or strategic initiatives.

Goals articulate specific strategic end points toward which activity id directed to accomplish the mission and vision focused on improvement of organizational performance but not on short-term financial gain.

Objectives are targets or key result areas that the organization aims for. It must:

- Be measurable and explicit.

- Specify a time for completion.

- Identify the person(s) responsible for completion. 